\title{
Limits of the processing view in accounting for dissociations among memory measures in a clinical population
}

\author{
BARBARA L. SCHWARTZ, RICHARD B. ROSSE, and STEPHEN I. DEUTSCH \\ Veterans Affairs Medical Center and Georgetown University School of Medicine, Washington, DC
}

\begin{abstract}
In three experiments, we examined the performance of patients with schizophrenia on implicit and explicit memory tests that have been shown to involve predominantly data-driven or predominantly conceptually driven processes. In Experiment 1, we compared the implicit tests of category production (conceptually driven) and word identification (data driven) and found that schizophrenic patients' performance on these tests did not differ from that of normal subjects. In Experiment 2, a comparison of the category-production and explicit cued-recall tests, both of which involve conceptual processes, showed that schizophrenic patients were impaired on the cued-recall test but not on the category-production test. In Experiment 3, a comparison of the word-identification and explicit graphemic cued-recall tests, both of which involve data-driven processes, showed that patients were impaired on the cued-recall test but not on the wordidentification test. The results of both Experiments 2 and 3 revealed a dissociation between implicit and explicit test performance under conditions in which the two tests involve similar types of processes. These results support theoretical views that distinguish implicit from explicit modes of retrieval.
\end{abstract}

Over the past decade, many studies have revealed striking dissociations in performance between explicit memory tests such as recall and recognition and implicit memory tests such as word-fragment or word-stem completion, in which performance changes are measured by repetitionpriming effects (for review, see Richardson-Klavehn \& Bjork, 1988; Schacter, 1987). One interpretation of findings of dissociations is that there is a fundamental difference in the type of memory involved in explicit and implicit memory tests (Graf \& Mandler, 1984; Graf \& Ryan, 1990; Schacter, 1990; Schacter, Cooper, \& Delaney, 1990; Tulving, 1983, 1985; Tulving \& Schacter, 1990). Explicit memory refers to the intentional retrieval of prior study episodes on tests that require conscious recollection, whereas implicit memory does not require conscious recollection of prior episodes (Graf \& Schacter, 1985; Schacter, 1987). Although there is some disagreement about whether implicit memory and explicit memory reflect the operation of different memory systems (Schacter et al., 1990; Shimamura, 1986; Squire, 1987; Tulving, 1983, 1985; Tulving \& Schacter, 1990) or different mental processes (e.g., Graf \& Mandler, 1984; Graf \& Ryan, 1990), it is suggested that the fundamental difference between these two types of memory lies in the distinction between conscious or intentional retrieval and un-

We thank Shahin Hashtroudi, Teresa Blaxton, Robert Proctor, Barry Stein, Eugene Winograd, and Mark McDaniel for their comments on an earlier version of this paper. We also thank Heather Handerson and Lori Friedman for their help with testing subjects. Correspondence should be addressed to B. L. Schwartz, Veterans Affairs Medical Center, Psychiatry Service (116A), 50 Irving St., N.W., Washington, DC 20422. conscious or unintentional retrieval of previously learned information.

A second interpretation of findings of dissociations between implicit and explicit test performance is the view that distinguishes data-driven from conceptually driven processes (Blaxton, 1989; Jacoby, 1983; Roediger \& Blaxton, 1987; Roediger, Srinivas, \& Weldon, 1989; Roediger, Weldon, \& Challis, 1989). Data-driven processes refer to cognitive activities that are guided by physical or perceptual features of items, whereas conceptually driven processes refer to cognitive activities guided by concepts or meaningful features of items. According to this view, which draws on the principle of transfer-appropriate processing (e.g., Morris, Bransford, \& Franks, 1977), memory performance in both explicit and implicit tests is determined by the match or overlap in the type of processing (data driven or conceptually driven) that is performed at study and test. Thus, in this view, there is no fundamental difference between explicit and implicit memory; the same form of memory underlies performance in each type of test.

Proponents of the data-driven and conceptually driven processing view suggest that many of the implicit tests studied thus far, such as word-fragment completion and word identification, involve predominantly data-driven processes, whereas explicit tests such as recall and recognition involve predominantly conceptually driven processes (Blaxton, 1989; Roediger, Weldon, \& Challis, 1989). Therefore, dissociations in performance between implicit and explicit tests arise because the tests engage different processes. It is suggested, however, that if one compares explicit and implicit memory tests that involve 
the same type of process, then dissociations in performance between the two types of tests would not occur.

Indeed, a study by Blaxton (1989) provides support for the data-driven and conceptually driven processing view. Blaxton found that conceptually driven study manipulations (e.g., generation of words) improved performance on tests that were shown to involve conceptually driven processes, regardless of whether the test was implicit (e.g., general knowledge) or explicit (e.g., semantic cued recall). Likewise, data-driven study manipulations (e.g., reading words) improved performance on implicit (e.g., word-fragment completion) and explicit (e.g., graphemic cued recall) tests that involved data-driven processes. The critical finding in Blaxton's study was that dissociations were observed between implicit tests that involved different types of processes and between explicit tests that involved different types of processes. Thus, her results suggest that it was the type of process (data vs. conceptual) rather than the kind of memory test (implicit vs. explicit) that accounted for dissociations among memory measures.

In the series of experiments reported here, we examined a clinical population to compare these two views of dissociations between implicit and explicit test performance. Schizophrenia is a neuropsychiatric disorder that lends itself particularly well to the study of conceptually driven processes in memory. Patients with schizophrenia have shown an impaired ability compared with normal control subjects to recall recently presented material in a variety of tasks, including serial recall, free recall, and cued recall (Bauman, 1971; Bauman \& Murray, 1968; Calev, 1984; Goldberg, Weinberger, Pliskin, Berman, \& Podd, 1989; Koh, 1978; Koh \& Kayton, 1974; Traupmann, 1975). It is suggested that the consistent recall failure in these patients is related to deficits in the use of elaborative and organizational processes, namely conceptually driven processes. For example, schizophrenic patients' recall performance is impaired under conditions that require active rehearsal (Oltmanns, 1978), imagery (Traupmann, 1975), generation (Koh \& Peterson, 1978), and categorization (Koh, Kayton, \& Berry, 1973; Russell \& Beekhuis, 1976) of words at study. In fact, deficits in organization are so wide ranging in these patients that they are observed on multiple indices of organization such as categorical clustering and subjective organization (Koh et al., 1973). Together, these results suggest that memory impairments in schizophrenic patients occur largely because these patients do not use the kinds of organizational or conceptual processes that benefit performance in explicit tests (for review, see Koh, 1978).

We propose that a comparison of implicit and explicit memory tests in schizophrenic patients will have some bearing on the two views of dissociations between explicit and implicit test performance. On the basis of the assumptions underlying each view, we would predict a different set of results when these tests are compared. If schizophrenic patients are impaired on conceptually driven tests but not on data-driven tests, regardless of whether the test is implicit or explicit, then this finding would support the view that it is the type of process (data vs. conceptual) rather than the type of memory test (implicit vs. explicit) that determines performance dissociations in this clinical population. If, on the other hand, schizophrenic patients are impaired on explicit tests but not on implicit tests, regardless of whether the test is classified as data driven or conceptually driven, then this finding would support the view that it is the type of memory test that is critical in determining performance dissociations in these patients.

We used category-production and word-identification tests to assess implicit memory. In the study phase of experiments that included the category-production test, subjects viewed a list of items belonging to different taxonomic categories. At test, subjects were presented with category titles and were asked to produce the first members of the category that came to mind (Gardner, Boller, Moreines, \& Butters, 1973; Graf, Shimamura, \& Squire, 1985; Kihlstrom, 1980; Rappold \& Hashtroudi, 1991; Srinivas \& Roediger, 1990). Category titles were of two types: titles that referred to category instances that subjects viewed at study (studied words) and those that referred to instances that were not shown at study (nonstudied words). Priming effects are observed in the category-production test when subjects produce more studied words than nonstudied words to the category titles. In the wordidentification test (Jacoby \& Dallas, 1981), words from the study phase and new words were presented very briefly, and subjects were asked to identify them. Priming effects are observed in this test when subjects identify more studied words than new, or nonstudied, words.

These tests were selected because prior research has shown that word identification and category production involve different amounts of data-driven and conceptually driven processes. The category-production test is considered a conceptually driven test because performance on this test is influenced by conceptually driven study manipulations such as generation of words, semantic versus nonsemantic orienting tasks, and organizational strategies (Hamann, 1990; Rappold \& Hashtroudi, 1991; Srinivas \& Roediger, 1990). For example, Rappold and Hashtroudi found that manipulation of organization by presenting category instances at study in a blocked rather than random order improved category-production performance. In addition, category-production performance is not affected by data-driven manipulations such as changes in the sensory modality between study and test (Srinivas \& Roediger, 1990). On the other hand, word identification is considered a data-driven test because performance in this test is affected by data-driven manipulations but not by conceptually driven ones (Jacoby, 1983; Jacoby \& Dallas, 1981).

In three experiments, we compared schizophrenic patients with normal control subjects on implicit and explicit memory tests that engaged different degrees of data-driven and conceptually driven processing. In Experiment 1, the type of memory test (implicit vs. explicit) was held constant and the type of process involved in the test (data vs. 
conceptual) was varied. Specifically, we compared schizophrenic patients' performance on two implicit memory tests: category production, which involves conceptual processes, and word identification, which involves data-driven processes. In Experiments 2 and 3, the type of process engaged in the test was held constant, and the type of memory test was varied. In Experiment 2, we compared performance on the category-production and cued-recall tests, both of which involve conceptual processes (e.g., Rappold \& Hashtroudi, 1991; Roediger \& Blaxton, 1987). In Experiment 3, we compared performance on the wordidentification and graphemic cued-recall tests, both of which depend predominantly on data-driven processes (Blaxton, 1989; Jacoby, 1983; Jacoby \& Dallas, 1981).

\section{EXPERIMENT 1}

In this experiment, schizophrenic patients and normal control subjects performed category-production and wordidentification tests. Organizational manipulations have an effect on category-production performance (Rappold \& Hashtroudi, 1991), and schizophrenic patients are impaired on memory tests that require organizational strategies (Koh et al., 1973). Consequently, we expected that schizophrenic patients would be impaired on the categoryproduction test. On the other hand, because schizophrenic patients are not impaired on tasks that minimize elaborative or organizational strategies (Koh, 1978), we did not expect them to be impaired on the word-identification test.

\section{Method}

Design and Materials. The design was a $2 \times 2$ factorial with group (schizophrenic patients and control subjects) as a between-subject variable and type of test (category production and word identification) as a within-subject variable.

The materials were selected from the Battig and Montague (1969) normative study in accordance with the procedures described by Rappold and Hashtroudi (1991, Experiment 5). Five words (e.g., monkey, camel, rabbit, sheep, mule) were selected from each of 16 categories (e.g., four-footed animals). Each word was four to six letters in length. These words were not ranked among the 10 most frequent instances of the category, but each word was listed by at least 10 subjects in the sample of 442 subjects used in the Battig and Montague study. The average rank of the selected instances was 21.8 (range: 11-40). The title of the category (e.g., four-footed animals) was used as the cue in the category-production test.

The 16 categories were divided into four lists of four categories each. This arrangement resulted in four lists of 20 items (4 categories of 5 items each). Two lists were used in the category-production test, and two were used in the word-identification test. In each test, one list of words served as studied words and the other served as nonstudied words. The lists were counterbalanced such that across subjects, each list was rotated across studied and nonstudied conditions and across the category-production and word-identification tests.

Subjects. Sixteen schizophrenic patients from the Washington, DC, Department of Veterans Affairs Medical Center and 16 normal control subjects participated in the experiment. Table 1 shows demographic features and vocabulary scores for the subjects in this experiment, as well as for the subjects in Experiments 2 and 3. All patients fulfilled the Diagnostic and Statistical Manual of Mental Disorders-III-Revised (DSM-III-R) criteria for chronic schizophrenia. These patients were screened for medical problems and showed no focal neurological disorders. Any patient with a signif-
Table 1

Demographic Features and Vocabulary Scores for Schizophrenic Patients and Control Subjects in Experiments 1, 2, and 3

\begin{tabular}{|c|c|c|c|c|}
\hline Group & Sex & Age & $\begin{array}{l}\text { Years of } \\
\text { Education }\end{array}$ & Vocabulary \\
\hline \multicolumn{5}{|c|}{ Experiment 1} \\
\hline Control & $15 \mathrm{M}, 1 \mathrm{~F}$ & 35.9 & 13.9 & 108.8 \\
\hline Schizophrenic & $15 \mathrm{M}, 1 \mathrm{~F}$ & 33.6 & 13.3 & 88.0 \\
\hline \multicolumn{5}{|c|}{ Experiment 2} \\
\hline Control & $15 \mathrm{M}, 1 \mathrm{~F}$ & 32.9 & 13.9 & 106.7 \\
\hline Schizophrenic & $14 \mathrm{M}, 2 \mathrm{~F}$ & 34.8 & 13.1 & 90.9 \\
\hline Schizophrenic* & $10 \mathrm{M}$ & 35.5 & 12.8 & 89.3 \\
\hline \multicolumn{5}{|c|}{ Experiment 3} \\
\hline Control & $24 \mathrm{M}$ & 36.3 & 13.0 & 87.8 \\
\hline Schizophrenic & $24 \mathrm{M}$ & 37.1 & 13.0 & 86.6 \\
\hline
\end{tabular}

*Schizophrenic patients who were given the cued-recall test only.

icant history of alcohol or drug abuse was excluded from the study. All patients were treated with conventional neuroleptic medication and were clinically stable at the time of testing.

The control subjects were paid volunteers who answered an advertisement. This group of subjects was matched to the group of schizophrenic patients on the variables of sex, age, and the number of years of education completed (all $p s>.05$ ). Scores from the Peabody Picture Vocabulary Test-Revised were available for 12 of the 16 subjects in each group. A comparison of the groups' scores on this test showed that control subjects had higher vocabulary scores than did schizophrenic patients $[t(22)=2.91, p<.01]$.

Procedure. All subjects were tested individually. Half of the subjects in each group performed the category-production test first followed by the word-identification test, and the remaining subjects performed the tests in the reverse order. One list of words was presented before the category-production test, and a different list of words was presented before the word-identification test. Before the experiment began, the subjects were told that they would be asked to perform a variety of tasks such as reading words and matching words with pictures according to their meaning. They were not informed that their memory for the lists of words presented at study would be tested at a later time. The study phase for each test was the same. The subjects were shown a list of 20 category instances printed in lowercase letters on $3 \times 5$ in. index cards. These words were presented only once to the subjects in a random order. The subjects were instructed to read each word aloud and rate how much they liked it using a 5-point scale that ranged from 1-like extremely to 5-dislike extremely (Graf et al., 1985). The subjects were permitted to rate the words at their own pace.

Immediately following the study phase, the subjects were given either the category-production or word-identification test. In the category-production test, the experimenter read each category title aloud and asked the subjects to come up with the first eight members of the category that came to mind. The experimenter instructed the subjects to produce eight words to ensure that they would produce words other than the most common instances of the category (Graf et al., 1985; Rappold \& Hashtroudi, 1991). The four category titles that referred to studied words and the four that referred to nonstudied words were read in a different random order for each subject. A practice trial was given before the test began, in which the experimenter said a sample category title ("relative") with three words that belonged to that category ("mother, father, and brother") and asked the subject to produce five more members of the category (Graf et al., 1985).

The word-identification test was performed using an IBM PC. In this test, the subjects were shown 20 studied words and 20 nonstudied words and were asked to identify each word aloud as it appeared on the computer monitor. These words were presented in 
a different random order for each subject. Before the main test list began, three blocks of 10 practice words were shown to set the exposure duration of words individually for each subject. Words in the first block were presented at increasingly shorter exposure durations beginning at $135 \mathrm{msec}$ and ending at $45 \mathrm{msec}$. All 10 words in the second block were presented at $35 \mathrm{msec}$. If the subjects identified between 3 and 7 words on this block of trials, then the exposure duration of words was kept at $35 \mathrm{msec}$ on the third block of trials and on the main test list. However, if the subjects performed outside this range, then the exposure duration of words was either increased or decreased on the third block of trials until they identified between 3 and 7 words. The mean exposure duration of words in the word-identification test was $41.7 \mathrm{msec}$ for the control subjects and $70.2 \mathrm{msec}$ for the schizophrenic patients.

\section{Results and Discussion}

The mean proportions of words produced in the categoryproduction test and identified in the word-identification test are shown in Table 2. An alpha level of .05 was set for all analyses reported in this article, unless otherwise stated.

Because there was no reliable effect of test order in this experiment, performance in each test was combined across test order. The proportions of nonstudied words produced or identified in the tests provide a measure of baseline performance. A comparison of the groups' baseline performance showed that schizophrenic patients did not differ reliably from control subjects either in the categoryproduction test $[t(30)=1.85]$ or in the word-identification test $[t(30)=0.76]$. Moreover, analyses comparing data from studied and nonstudied conditions revealed a main effect of study in both the category-production test $\left[F(1,30)=40.57, M S_{e}=2.78\right]$ and the wordidentification test $\left[F(1,30)=47.28, M S_{\mathrm{e}}=5.76\right]$. These results showed that a significant amount of priming occurred in each test.

Of greater importance in this experiment is the comparison of priming between the category-production and word-identification tests. To obtain a measure of priming in each test, we subtracted baseline performance from the proportions of studied words produced or identified. Priming performance is shown as a difference score in Table 2. A $2 \times 2$ analysis of variance (ANOVA) with group and type of test as variables yielded no main effect of group $(F<1)$, no main effect of type of test $\left[F(1,30)=2.59, M S_{\mathrm{e}}=9.17\right]$, and no interaction between these variables $(F<1)$. These results indicate that priming in both category production and word identification was unimpaired in the schizophrenic patients. These

Table 2

Proportions of Words Produced in the Category-Production

Test and Identified in the Word-Identification Test for Schizophrenic Patients and Control Subjects in Experiment 1

\begin{tabular}{lccccc} 
& \multicolumn{4}{c}{ Test } \\
\cline { 2 - 3 } & \multicolumn{2}{c}{ Category Production } & & \multicolumn{2}{c}{ Word Identification } \\
\cline { 2 - 3 } \cline { 5 - 6 } Control & Schizophrenic & Control & Schizophrenic \\
Studied & .26 & .21 & .65 & .53 \\
Nonstudied & .13 & .08 & & .42 & .35 \\
Difference & .13 & .13 & & .23 & .18 \\
\hline
\end{tabular}

patients showed normal implicit memory performance, regardless of whether the test involved conceptually driven or data-driven processes.

The finding that the schizophrenic patients required longer exposure durations of words in the wordidentification test $(70.2 \mathrm{msec})$ than did the control subjects $(41.7 \mathrm{msec})$ is consistent with previous findings that these patients have trouble with tasks requiring rapid processing of information (for review, see Schwartz, 1990). Nevertheless, the schizophrenic patients showed normal priming performance in word identification, as well as in category production. Because the materials in this experiment were nearly identical to those in the Rappold and Hashtroudi (1991) study, we can compare priming performance across the two studies. The comparable condition in the Rappold and Hashtroudi study was the random-presentation condition of Experiment 5. In their study, priming was .21 in word identification and .12 in category production for normal subjects. In our study, priming was .18 in word identification and .13 in category production for the schizophrenic patients. The finding that priming in category production was unimpaired in schizophrenic patients suggests that these patients may not have a fundamental deficit in the use of conceptually driven processes but may have difficulty using these processes when required to explicitly retrieve words from a prior study occasion. The next experiment tested this possibility.

\section{EXPERIMENT 2}

The purpose of this experiment was to compare explicit and implicit memory performance in schizophrenic patients, using two tests that involve conceptually driven processes. We used category-production and cued-recall tests because previous findings indicated that performance in each of these tests is affected by conceptually driven manipulations such as elaboration and organization (Dallett, 1964; Hamann, 1990; Rappold \& Hashtroudi, 1991; Srinivas \& Roediger, 1990). If schizophrenic patients cannot engage in conceptually driven processing, then we would expect them to show deficits on both the categoryproduction and cued-recall tests. If, on the other hand, schizophrenic patients are impaired in conceptually driven processing only in the explicit retrieval of words, then we should observe a dissociation between explicit and implicit memory performance. Schizophrenic patients should be impaired on the cued-recall test but not on the categoryproduction test.

In this experiment, the subjects received the categoryproduction test before the cued-recall test. The order of testing was confounded to ensure that learning in the second test would be unintentional. However, this raises the possibility that cued-recall performance for the schizophrenic patients will be unusually low because of the interfering effects of the preceding category-production test. This concern stems from findings that schizophrenic patients are particularly sensitive to interference in a vari- 
ety of memory and cognitive tasks (Bauman \& Kolisnyk, 1976; Lang \& Buss, 1965). To examine this possibility, we tested a separate group of schizophrenic patients on the cued-recall test only, without the preceding categoryproduction test.

\section{Method}

Design and Materials. The design was a $2 \times 2$ mixed factorial with group (schizophrenic patients and control subjects) as a between-subject variable and type of test (category production and cued recall) as a within-subject variable. The category instances and the category-production test were the same as those in Experiment 1 . The cued-recall test used in this experiment was identical to the category-production test, with the exception of the instructions given to the subjects. In the cued-recall test, the subjects were instructed to use the category title to help them remember words that they had studied. The subjects were informed that some of the category titles would not refer to previously presented words.

Subjects. Twenty-six schizophrenic patients and 16 control subjects participated in this experiment. Of the 26 patients, 16 patients were given both the category-production and cued-recall tests and 10 were given the cued-recall test only. The patients and control subjects were recruited from the same pool of subjects and fulfilled the same cr teria as those who participated in Experiment 1. As is shown in Table 1, the group of control subjects was matched to the group of 16 patients on the variables of age and the number of years of education they completed ( $p s>.05$ ). However, the control subjects had higher vocabulary scores on the Peabody Picture Vocabulary Test-Revised than did the patients $[t(30)=-3.28$, $p<.01]$. The two groups of patients were similar to each other in terms of age, level of education, and vocabulary scores.

Procedure. Each subject was tested individually. Before the experiment began, the subjects were given the same general instructions as those described in Experiment 1. The subjects who received both of the tests were given the category-production test first, followed by the cued-recall test.

The study phase was the same for each test. The subjects were shown 20 words ( 5 words from four different categories) in a random order and were asked to read each word aloud and rate how much they liked it using the 5-point scale described in Experiment 1. The subjects were not told that their memory for these words would be tested. Immediately after the first list of words was presented, the subjects were given the category-production test. After they completed the category-production test, the subjects were shown the second list of words. Their memory for these words was tested immediately in cued recall. A practice trial preceded the cued-recall test, in which the experimenter gave the subjects several category exemplars ("mother, father, and brother") followed by a category title ("relative") and asked the subjects to recall the words that belonged to that category.

\section{Results and Discussion}

Table 3 shows the proportions of words produced in the category-production test and recalled in the cued-recall test. The measure of priming in the category-production test is the difference between the proportion of studied words and the proportion of nonstudied words produced to category titles. An analysis comparing data from the studied and nonstudied conditions revealed a significant amount of priming in the category-production test $\left[F(1,30)=52.42, M S_{e}=2.86\right]$. The measure of corrected cued recall is the difference between the proportion of studied and nonstudied words recalled to the category titles. As can be seen in Table 3, neither the schizophrenic patients nor the control subjects "recalled" a word from the list of nonstudied words.

An analysis of the priming and cued-recall data for the subjects who received the two tests in succession revealed a main effect of group $\left[F(1,30)=7.87, M S_{\mathrm{e}}=9.45\right]$, a main effect of type of test $\left[F(1,30)=87.54, M S_{\mathrm{e}}=\right.$ 4.98], and an interaction between these variables $\left[F(1,30)=4.30, M S_{\mathrm{e}}=4.98\right]$. Simple effects tests showed that cued-recall performance differed for the patients and the control subjects $\left[F(1,30)=9.56, M S_{\mathrm{e}}=\right.$ 9.18], whereas category-production performance did not $\left[F(1,30)=1.52, M S_{\mathrm{e}}=5.25\right]$. In addition, as shown in Table 3, cued-recall performance for the group of the patients who received the cued-recall test only $(.36)$ did not differ reliably from the performance of the patients who received the two tests $[.33 ; t(24)=-.34]$. These results indicate that the patients' cued-recall performance was unaffected by the preceding category-production test.

One methodological concern that might be raised about Experiment 2 is that the control subjects had higher vocabulary scores, on average, than did the schizophrenic patients. Therefore, differences in cued-recall performance could be attributed to differences in verbal knowledge rather than to differences in explicit memory performance. To address this concern, another experiment was conducted in which we examined explicit memory performance in 15 schizophrenic patients and 15 normal subjects, who were matched to the group of patients in terms of age, sex, and performance on the vocabulary subscale of the Wechsler Adult Intelligence Scale-Revised. Explicit memory was tested using the California Verbal Learning

Table 3

Proportions of Words Produced in the Category-Production

Test and Recalled in the Cued-Recall Test for Schizophrenic Patients and Control Subjects in Experiment 2

\begin{tabular}{|c|c|c|c|c|c|}
\hline & \multicolumn{5}{|c|}{ Test } \\
\hline & \multicolumn{2}{|c|}{ Category Production } & \multicolumn{3}{|c|}{ Cued Recall } \\
\hline & Control & Schizophrenic & Control & Schizophrenic & Schizophrenic* \\
\hline Studied & .31 & .24 & .50 & .33 & .36 \\
\hline Nonstudied & .13 & .11 & .00 & .00 & .00 \\
\hline Difference & .18 & .13 & .50 & .33 & .36 \\
\hline
\end{tabular}

*Schizophrenic patients who were given the cued-recall test only 
Test (Delis, Kramer, Kaplan, \& Ober, 1987), which consists of multiple explicit memory paradigms to assess the retrieval of categorized information. Specifically, the subjects studied a list of 16 category instances, 4 words from each of four categories (spices and herbs, fruits, tools, and clothing) and were tested in multitrial free-recall, immediate and delayed cued- and free-recall, and recognition memory paradigms. To summarize the results of this experiment, the schizophrenic patients were impaired in all test conditions compared with the control subjects, thereby suggesting that explicit memory is impaired in these patients even when their vocabulary scores are matched to those of normal subjects. These results suggest further that the schizophrenic patients' impairment in cued recall in Experiment 2 cannot be attributed simply to their lower level of vocabulary.

Thus, the main finding of Experiment 2 was that the schizophrenic patients were impaired on the cued-recall test but not on the category-production test. The finding that cued-recall performance was impaired in these patients replicated the results of numerous studies showing recall deficits in this group (e.g., Koh, 1978). In addition, the finding that the schizophrenic patients performed normally on the category-production test replicated the results of Experiment 1. The important point is that the disorder of schizophrenia produced a dissociation in performance between two tests-category production and cued recall-that have previously been shown to involve conceptual processes. These results suggest that schizophrenic patients have difficulty engaging in conceptually driven processing in the explicit retrieval of previously acquired words.

\section{EXPERIMENT 3}

In the previous experiment, we demonstrated a dissociation between implicit and explicit test performance in schizophrenic patients using tests that depend on conceptual processes. These findings leave open the possibility that schizophrenic patients are not impaired in explicit retrieval, in general, but instead are impaired only on explicit tests that involve conceptual processes. In the experiment reported here, we explored implicit and explicit test performance in this patient group by comparing two tests that involve data-driven processes: word identification and graphemic cued recall.

In the graphemic cued-recall test, subjects are shown words that are physically similar (e.g., PUPPY) to words that they had previously studied (e.g., POPPY) and are asked to use these words to help them remember words from the study list. The unique feature of this test is that subjects are instructed to remember study words that look like, but do not share the same meaning as, the words shown at test. Blaxton (1989) found that performance in the graphemic cued-recall test is influenced by data-driven manipulations such as changes in sensory modality between study and test, but performance is not influenced by conceptual manipulations such as levels of processing or self-generation. Consequently, graphemic cued recall is classified as a data-driven test. As noted earlier, word identification is also considered a data-driven test (e.g., Jacoby, 1983). If schizophrenic patients are impaired in the explicit retrieval of previously presented words, regardless of whether the test involves conceptual or datadriven processes, then we should observe a dissociation between implicit and explicit test performance. Patients should be impaired on the graphemic cued-recall test but show normal priming in the word-identification test.

\section{Method}

Design and Materials. The design was a $2 \times 2$ factorial with group (schizophrenic patients and control subjects) and type of test (word identification and graphemic cued recall) as between-subject variables. Twelve subjects were tested in each condition.

The materials consisted of 80 target words (e.g., CASTLE, ONION, and POPPY) and 80 "graphemic" cues, each of which was physically similar to one of the target words (e.g., CATTLE, UNION, and PUPPY). These materials were selected from the pool of materials developed by Blaxton $(1989,1992)$. Each target word used in this experiment was five to eight letters in length. The 80 target words were divided into four lists of 20 words each. The average normative frequency (Thorndike $\&$ Lorge, 1944) of words was equated across the four lists (Lists $1-3, M=24$; List $4, M=23$ ). Two of the four lists were used in the word-identification test, and two were used in the graphemic cued-recall test. In each test, one list of words was shown at study (studied words) and the other list consisted of nonstudied words. Across subjects, each list of words served equally often in the studied and nonstudied conditions and in the two test conditions.

Subjects. Twenty-four male schizophrenic patients and 24 male control subjects were recruited from the same pool of subjects as those in Experiment 1. The schizophrenic patients and the control subjects were matched in terms of age, sex, years of education completed, and performance on the Peabody Picture Vocabulary Test-Revised (see Table 1). In addition, a 2 (group) $\times 2$ (type of test) ANOVA was performed on the ages, years of education completed, and vocabulary scores to determine whether there were any differences among the four groups of subjects. The results of these analyses yielded no significant main effects or significant interactions (all $F \mathrm{~s}<1.60$ ), indicating that the groups did not differ reliably on these variables.

Procedure. All subjects were tested individually. The experiment's purpose and the general instructions given to the subjects were the same as in Experiment 1. At acquisition, 20 words printed in lowercase letters on $5 \times 8$ in. cards were presented one at a time. The subjects were asked to read each word aloud. In contrast to the previous experiments, the subjects did not rate the pleasantness of these words. Immediately after acquisition, the subjects were given either the word-identification or graphemic cued-recall test. In the graphemic cued-recall test, 20 studied words and 20 nonstudied words were presented in a random order on a sheet of paper. The subjects were instructed to use these words as cues to help them remember words from the study list. They were told that the cues in this test looked like words they had studied but that these cues did not share the same meaning with study words. The subjects completed the cued-recall test at their own pace. The procedural details of the word-identification test were identical to those in Experiment 1.

\section{Results and Discussion}

The proportions of words identified in the wordidentification test and recalled in the graphemic cued-recall test are shown in Table 4. A comparison of performance 
Table 4

Proportions of Words Identified in the Word-Identification Test and Recalled in the Graphemic Cued-Recall Test for Schizophrenic Patients and Control Subjects in Experiment 3

\begin{tabular}{lccccc}
\hline & \multicolumn{3}{c}{ Test } \\
\cline { 2 - 3 } & \multicolumn{2}{c}{ Word Identification } & & Graphemic Cued Recall \\
\cline { 2 - 3 } Control & Schizophrenic & & Control & Schizophrenic \\
Nonstudied & .46 & .70 & & .57 & .30 \\
Difference & .23 & .44 & & .00 & .01 \\
& .69 & .26 & & .57 & .29
\end{tabular}

in the studied and nonstudied conditions revealed a main effect of study $\left[F(1,22)=29.69, M S_{\mathrm{e}}=9.60\right]$, showing that a significant amount of priming occurred in this test. Priming is shown as a difference score in Table 4.

The results of this experiment clearly reveal a dissociation between implicit and explicit test performance. Priming in word identification was nearly the same for the patients (.26) and the control subjects $(.23)$, whereas cuedrecall performance for studied words was lower for the patients $(.30)$ than for the control subjects $(.57)$. These findings were confirmed by a 2 (group) $\times 2$ (type of test) ANOVA, which showed a main effect of type of test $\left[F(1,44)=10.57, M S_{\mathrm{e}}=17.05\right]$ and an interaction between group and type of test $\left[F(1,44)=6.16, M S_{\mathrm{e}}=\right.$ 17.05]. The findings reported here show a dissociation between implicit and explicit test performance using tests that involve data-driven processes. Schizophrenic patients are impaired in the explicit recall of previously acquired words, regardless of whether the test involves conceptual or data-driven processes.

\section{GENERAL DISCUSSION}

The main finding to emerge from these experiments is that the schizophrenic patients performed normally on implicit tests, whereas their performance was impaired on explicit tests. The performance of the schizophrenic patients did not differ from that of the normal control subjects on the word-identification (Experiments 1 and 3) or the category-production (Experiments 1 and 2) tests, suggesting that implicit memory is unimpaired in these patients regardless of whether the test involves data-driven or conceptually driven processes. In contrast, the schizophrenic patients showed impaired cued-recall performance in a test that involved conceptual processes (Experiment 2) and one that involved data-driven processes (Experiment 3). Of greater theoretical interest is the finding of a dissociation between implicit and explicit test performance under conditions in which the two tests being compared involved similar types of processes. Experiment 2 showed a dissociation between category production and cued recall, two tests that involve conceptual processes, and Experiment 3 showed a dissociation between word identification and graphemic cued recall, two tests that involve data-driven processes.

The dissociations observed here have implications for the different views of dissociations among memory mea- sures discussed in the introduction. According to the processing view that distinguishes between data-driven and conceptually driven processes, an experimental variable will have different effects on two tests when one test involves data-driven processes and the other involves conceptually driven processes. On the other hand, proponents of this view contend that an experimental variable should have similar effects on the performance of two tests that involve the same type of process, that is, if both tests involve data-driven processes or if both involve conceptually driven processes (e.g., Blaxton, 1989; Srinivas \& Roediger, 1990). Clearly, the finding that the disorder of schizophrenia produced a dissociation between implicit and explicit test performance when the two tests involved similar types of processes, namely either conceptual or data-driven processes, is inconsistent with the predictions of this view.

The results reported here support the idea that there is a fundamental difference between explicit, or conscious, retrieval and implicit, or unconscious, retrieval of previously acquired information. Several investigators account for the dissociations between explicit and implicit test performance by suggesting that explicit and implicit tests involve different mental processes (Graf \& Mandler, 1984; Graf \& Ryan, 1990; Mandler, 1988), whereas other investigators account for dissociations by postulating the existence of separate memory systems (Schacter, 1990; Squire, 1987; Tulving, 1983, 1985; Tulving \& Schacter, 1990). For example, proponents of a memory systems view (e.g., Tulving and Schacter, 1990) might suggest that the dissociation between category-production and cued-recall performance reflects the operation of two distinct systems: Priming in category production (conceptual priming) may reflect modification of semantic knowledge and, as such, is mediated by the semantic system, whereas cued-recall performance is mediated by the episodic system, which handles information about temporally dated episodes and the spatial-temporal relations among them (Tulving, 1972, 1983).

Views that distinguish explicit retrieval of contextual and spatial-temporal information from implicit retrieval of previously learned information may have particular relevance in understanding memory disorders in schizophrenia. The results reported here showed that schizophrenic patients were impaired on explicit, but not implicit, memory tests that involved conceptually driven processes. These results suggest that schizophrenic patients may not have deficits in conceptual or organizational processes per se but may have difficulty using these types of processes in tests that require retrieval of contextual or spatial-temporal information. There is some evidence that supports this suggestion. For example, it has been noted that schizophrenic patients do not show organizational deficits when simply sorting or categorizing items (Koh, Kayton, \& Schwartz, 1974; Russell \& Beekhuis, 1976). When asked to sort a list of unrelated words or a list of categorized words into different piles, patients' sorting schemes and the extent to which words were sorted 
by category norms (e.g., Battig \& Montague, 1969) did not differ from those of normal subjects. In fact, Russell and Beekhuis noted that "when a measure independent of episodic memory and therefore presumably uncontaminated by processes involved in the search and retrieval of occurrence information is used, evidence suggesting any abnormality in schizophrenic lexical store structure is not forthcoming"' (Russell \& Beekhuis, 1976, p. 528).

Further evidence that these patients have difficulty on tests that require retrieval of contextual or spatial-temporal information comes from the finding of impaired memory for the temporal order of events. Schizophrenic patients were less accurate than normal subjects in judging the relative recency of previously presented words using the recency discrimination test (Schwartz, Deutsch, Cohen, Warden, \& Deutsch, 1991). Finally, there is some suggestion that schizophrenic patients are impaired in remembering the source of recently acquired information. Harvey (1985) found that schizophrenic patients with thought disorders had trouble discriminating whether a previously presented item was one they had actually said or one that they had only imagined themselves to have said. Thus, evidence that these patients are impaired in remembering the temporal order and the source of recently presented words suggests that schizophrenic patients have problems with the explicit retrieval of contextual and spatial-temporal information.

The pattern of implicit and explicit test performance found in schizophrenic patients is similar to that found in other memory-impaired populations. For instance, amnesic patients perform normally on implicit tests despite their impaired performance on explicit tests (e.g., Cermak, Talbot, Chandler, \& Wolbarst, 1985; Graf, Squire, \& Mandler, 1984; Jacoby \& Witherspoon, 1982; see Shimamura, 1986, for a review). Indeed, findings that amnesic patients show normal priming on a variety of tasks has provided critical evidence for the distinction between implicit and explicit retrieval of previously acquired items. The findings in amnesia that are relevant to the present results are those in which amnesic patients show normal priming in the category-production test but are impaired on recall tests (Gardner et al., 1973; Graf et al., 1985). These findings, like those reported here, reveal a dissociation in performance between implicit and explicit tests when the two tests appear to engage similar processes. However, recent evidence suggests that memoryimpaired patients are not uniformly unimpaired in conceptual implicit memory tasks. Blaxton (1992) found that patients with left temporal lobe epilepsy failed to show conceptual transfer in the category-production test. Thus, the full range of conditions under which priming in conceptual implicit tasks is normal in memory-impaired populations is yet to be determined.

There are also parallels between the memory deficits found in schizophrenia and those found in normal aging. Older adults' performance on explicit memory tasks is inferior to that of younger adults, whereas their performance on a wide range of implicit memory tasks such as word-stem completion, word identification, and category production is unaffected (Light \& Singh, 1987; Mitchell, 1989; see Graf, 1990, and Howard, 1988, for reviews). We attributed the explicit memory deficits in schizophrenic patients, in part, to their difficulty in remembering spatial-temporal and contextual information. Similar explanations have been proposed for explicit memory deficits in older subjects (Burke \& Light, 1981), who are impaired in remembering contextual details such as spatial location (e.g., Light \& Zelinski, 1983) and source information (Cohen \& Faulkner, 1989; Hashtroudi, Johnson, \& Chrosniak, 1989; McIntyre \& Craik, 1987). In fact, Dywan and Jacoby (1990) found that sourcemonitoring deficits in elderly subjects were related to their deficits on free-recall tasks. Although there are unique cognitive deficits associated with schizophrenia and with normal aging, commonalities in impaired and spared memory functions may point to common mechanisms of memory failure.

In summary, the findings reported here show some parallels between schizophrenic patients and other memory-impaired populations: Schizophrenic patients were impaired on explicit memory tests but not on implicit tests. In addition, we observed a clinical dissociation in performance between tests that involved conceptually driven processes (category production and cued recall) and between those that involved data-driven processes (word identification and graphemic cued recall). The dissociation in performance between two tests that involve similar types of processes seems inconsistent with the datadriven and conceptually driven view of dissociations between implicit and explicit memory performance. These results suggest that views that highlight the difference between conscious and unconscious retrieval of previously experienced events may be needed to account for the dissociations between explicit and implicit memory performance.

\section{REFERENCES}

Battig, W. F., \& Montague, W. E. (1969). Category norms for verbal items in 56 categories: A replication and extension of the Connecticut category norms. Journal of Experimental Psychology Monographs, 80(3, Pt. 2).

Bauman, E. (1971). Schizophrenic short-term memory: A deficit in subjective organization. Canadian Journal of Behavioral Science, $\mathbf{3}$, 55-65.

Bauman, E., \&olisnyk, E. (1976). Interference effects in schizophrenic short-term memory. Joumal of Abnormal Psychology, 85, 303-308.

Bauman, E., \& Murray, D. J. (1968). Recognition versus recall in schizophrenia. Canadian Journal of Psychology, 22, 18-25.

BLAXTON, T. A. (1989). Investigating dissociations among memory measures: Support for a transfer-appropriate processing framework. Journal of Experimental Psychology: Learning, Memory, \& Cognition, $15,657-668$.

Blaxton, T. A. (1992). Dissociations among memory measures in memory-impaired subjects: Evidence for a processing account of memory. Memory Cognition, 20, 549-562.

Burke, D. M., \& Light, L. L. (1981). Memory and aging: The role of retrieval processes. Psychological Bulletin, 90, 513-546.

Calev, A. (1984). Recall and recognition in chronic nondemented 
schizophrenics: Use of matched tasks. Journal of Abnormal Psychology, 93, 172-177.

Cermak, L. S., Talbot, N., Chandler, K., \& Wolbarst, L. R (1985). The perceptual priming phenomenon in amnesia. Neuropsychologia, 23, 615-622.

CohEN, G., \& FaulKner, D. (1989). Age differences in source forgetting: Effects on reality monitoring and on eyewitness testimony. Aging \& Memory, 4, 10-17.

DALLETT, K. M. (1964). Number of categories and category information in free recall. Joumal of Experimental Psychology, 68, 1-12.

Delis, D. C., Kramer, J. H., Kaplan, E., Ober, B. A. (1987) The Califormia Verbal Leaming Test: Manual. New York: The Psychological Corporation.

DYWAN, J., \& JACOBY, L. (1990). Effects of aging on source monitoring: Differences in susceptibility to false fame. Aging \& Memory, 5 , 379-387

Gardner, H., Boller, F., Moreines, J., \& Butters, N. (1973) Retrieving information from Korsakoff patients: Effects of categori cal cues and reference to the task. Cortex, 9, 165-175.

Goldberg, T. E., Weingerger, D. R., Pliskin, N. H., Berman, K. F., \&ODD, M. H. (1989). Recall memory deficit in schizophrenia: A possible manifestation of prefrontal dysfunction. Schizophrenia $R e$ search, 2, 251-257.

GraF, P. (1990). Life-span changes in implicit and explicit memory. Bulletin of the Psychonomic Society, 28, 353-358.

GraF, P., \& Mandler, G. (1984). Activation makes words more accessible, but not necessarily more retrievable. Journal of Verbal Learning \& Verbal Behavior, 23, 553-568

Graf, P., \& RYan, L. (1990). Transfer-appropriate processing for implicit and explicit memory. Joumal of Experimental Psychology: Learning, Memory, \& Cognition, 16, 978-992.

Graf, P., \&Chacter, D. L. (1985). Implicit and explicit memory for new associations in normal and amnesic subjects. Journal of Experimental Psychology: Learning, Memory, \& Cognition, 11, 501-518

Graf, P., Shimamura, A. P., Souire, L. R. (1985). Priming across modalities and priming across category levels: Extending the domain of preserved function in amnesia. Journal of Experimental Psychology: Learning, Memory, \& Cognition, 11, 386-396.

Graf, P., Squire, L. R., \& Mandler, G. (1984). The information that amnesic patients do not forget. Journal of Experimental Psychology: Learning, Memory, \& Cognition, 10, 164-178.

HamanN, S. B. (1990). Level-of-processing effects in conceptually driven implicit tasks. Journal of Experimental Psychology: Learning, Memory, \& Cognition, 16, 970-977.

HaRVEY, P. D. (1985). Reality monitoring in mania and schizophrenia: The association of thought disorder and performance. Journal of Nervous \& Mental Disease, 173, 67-73.

Hashtroudi, S., Johnson, M. K., Chrosniak, L. D. (1989). Aging and source monitoring. Aging \& Memory, 4, 106-112.

How ARD, D. V. (1988). Implicit and explicit assessment of cognitive aging. In C. J. Brainerd \& M. L. Howe (Eds.), Cognitive development in adulthood (pp. 3-37). New York: Springer-Verlag.

JACOBY, L. L. (1983). Remembering the data: Analyzing interactive processes in reading. Journal of Verbal Learning \& Verbal Behavior, 22, 485-508.

JACOBY, L. L., \& DALLAS, M. (1981). On the relationship between autobiographical memory and perceptual leaning. Joumal of Experimental Psychology: General, 110, 306-340.

JACOBY, L. L., \& WITHERSPOON, D. (1982). Remembering without awareness. Canadian Journal of Psychology, 36, 300-324.

Kinlstrom, J. F. (1980). Posthypnotic amnesia for recently learned material: Interactions with "episodic" and "semantic" memory. Cognitive Psychology, 12, 227-251.

KoH, S. D. (1978). Remembering of verbal materials by schizophrenic young adults. In S. Schwartz (Ed.), Language and cognition in schizophrenia (pp. 55-99). Hillsdale, NJ: Erlbaum.

KoH, S. D., Karton, L. (1974). Memorization of "unrelated" word strings by young nonpsychotic schizophrenics. Journal of Abnormal Psychology, 83, 14-22.

Koh, S. D., Kayton, L., \& Berry, R. (1973). Mnemonic organiza- tion in young nonpsychotic schizophrenics. Journal of Abnormal Psychology, 81, 299-310.

KoH, S. D., Kayton, L., \& SchwarTZ, C. (1974). The structure of word-storage in the permanent memory of nonpsychotic schizophrenics. Journal of Consulting \& Clinical Psychology, 42, 879-887.

Koh, S. D., \& Peterson, R. A. (1978). Encoding orientation and the remembering of schizophrenic young adults. Journal of Abnormal Psychology, 87, 303-313.

Lang, P. J., \& Buss, A. H. (1965). Psychological deficit in schizophrenia: II. Interference and activation. Journal of Abnormal Psychology, 70, 77-106

Light, L. L., \& Singh, A. (1987). Implicit and explicit memory in young and older adults. Journal of Experimental Psychology: Learning, Memory, \& Cognition, 13,531-541.

LiGHT, L. L., \& ZeLINSKI, E. M. (1983). Memory for spatial information in young and old adults. Developmental Psychology, 19, 901-906

MANDleR, G. (1988). Memory: Conscious and unconscious. In P. R. Solomon, G. R. Goethals, C. M. Kelley, \& B. R. Stephens (Eds.). Memory: Interdisciplinary approaches (pp. 84-106). New York: Springer-Verlag

MCINTYRE, J. S., \& Craik, F. I. M. (1987). Age differences in memory for item and source information. Canadian Journal of Psychology, 41, 175-192.

MitChelL, D. B. (1989). How many memory systems?: Evidence from aging. Journal of Experimental Psychology: Learning, Memory, \& Cognition, 15, 31-49.

Morres, C. D., Bransford, J. D., \& Franks, J. J. (1977). Levels of processing versus transfer appropriate processing. Journal of Verbal Learning \& Verbal Behavior, 16, 519-533.

OLtManNS, T. F. (1978). Selective attention in schizophrenic and manic psychoses: The effects of distraction on information processing. Journal of Abnormal Psychology, 87, 212-225.

RAPPOLD, V. A., \& HaShTROUd, S. (1991). Does organization improve priming? Journal of Experimental Psychology: Learning, Memory, \& Cognition, 17, 103-114.

Richardson-Klanehn, A., \& Bjork, R. A. (1988). Measures of memory. Annual Review of Psychology, 39, 475-543.

Roediger, H. L., III, \& Blaxton, T. A. (1987). Retrieval modes produce dissociations in memory for surface information. In D. S. Gorfein \& R. R. Hoffman (Eds.), Memory and cognitive processes: The Ebbinghaus Centennial Conference (pp. 349-379). Hillsdale, NJ: Erlbaum.

Rofdiger, H. L., III, Srinivas, K., \& Weldon, M. S. (1989). Dissociations between implicit measures of retention. In $\mathrm{S}$. Lewandowsky, J. C. Dunn, \& K. Kirsner (Eds.), Implicit memory: Theoretical issues (pp. 67-84). Hillsdale, NJ: Erlbaum.

Roediger, H. L., III, Weldon, M. S., \& Challis, B. H. (1989). Explaining dissociations between implicit and explicit measures of retention: A processing account. In H. L. Roediger III \& F. I. M. Craik (Eds.), Varieties of memory and consciousness: Essays in honor of Endel Tulving (pp. 3-41). Hillsdale, NJ: Erlbaum.

RusSell, P. N., \& BEEKHUIS, M. E. (1976). Organization in memory A comparison of psychotics and normals. Journal of Abnormal Psychology, 85, 527-534

SCHACTER, D. L. (1987). Implicit memory: History and current status Journal of Experimental Psychology: Learning, Memory, \& Cognifion, 13, 501-518

SChacter, D. L. (1990). Perceptual representation systems and implicit memory: Toward a resolution of the multiple memory systems debate. In A. Diamond (Ed.), Development and neural bases of higher cognitive functions. Annals of the New York Academy of Sciences, 608, 543-571.

Schacter, D. L., Cooper, L. A., \& Delaney, S. M. (1990). Implicit memory for unfamiliar objects depends on access to structural descriptions. Journal of Experimental Psychology: General, 119, 5-24

SCHWARTZ, B. D. (1990). Early information processing in schizophrenia Psychiatric Medicine, 8, 73-94.

Schwartz, B. L., Deutsch, L. H., Cohen, C., Warden, D., \& 
Deutsch, S. I. (1991). Memory for temporal order in schizophrenia. Biological Psychiatry, 29, 329-339.

Shimamura, A. P. (1986). Priming effects in amnesia: Evidence for a dissociable memory function. Quarterly Journal of Experimental Psychology, 38A, 619-644.

SQUIRE, L. R. (1987). Memory and brain. New York: Oxford University Press.

SRINIVAS, K., \& Roediger, H. L., III (1990). Classifying implicit memory tests: Category association and anagram solution. Joumal of Memory \& Language, 29, 389-412.

THORNDIKE, E. L., \& LORGE, I. (1944). The teachers' word book of 30,000 words. New York: Columbia University.

TraupmanN, K. L. (1975). Effects of categorization and imagery on recognition and recall by process and reactive schizophrenics. Journal of Abnormal Psychology, 84, 307-314.
TulviNG, E. (1972). Episodic and semantic memory. In E. Tulving \& W. Donaldson (Eds.), Organization of memory (pp. 381-403). New York: Academic Press.

Tulving, E. (1983). Elements of episodic memory. Oxford: Clarendon Press.

Tulving, E. (1985). How many memory systems are there? American Psychologist, 40, 385-398.

Tulving, E., \& Schacter, D. L. (1990). Priming and human memory systems. Science, 247, 301-306.

(Manuscript received June 25, 1991; revision accepted for publication July 7,1992 .) 